\title{
28 Research Suare \\ Identification of SLC14A1 (UT-B) gene \\ rearrangement in urothelial carcinoma of the bladder
}

\section{Zhongying Guo}

Nanjing Medical University

Xiaobing Niu

Nanjing Medical University

Guangbo Fu

Nanjing Medical University

Baoxue Yang

Peking University

Guangping Chen ( $\square$ gchen3@emory.edu )

Emory University School of Medicine https://orcid.org/0000-0003-4178-4529

\section{Su'an Sun}

Nanjing Medical University

\section{Research article}

Keywords: Bladder, Urothelial cancer, Fluorescence in situ hybridization, Gene rearrangement

Posted Date: January 29th, 2020

DOl: https://doi.org/10.21203/rs.2.22209/v1

License: (c) (1) This work is licensed under a Creative Commons Attribution 4.0 International License. Read Full License 


\section{Abstract}

Background: Bladder cancer ( $\mathrm{BCa}$ ) is a common and deadly disease. Over the past decade, a number of genetic alterations have been reported in $\mathrm{BCa}$. Bladder urothelium expresses abundant urea transporter UT-B encoded by SIc14a1 gene at 18q12.3 locus, which plays an important role in preventing high concentrated urea-caused cell injury. Early genome-wide association studies (GWAS) showed that UT-B gene mutations are genetically linked to the urothelial bladder cancer.

Methods: In this study, using a fluorescence in situ hybridization (FISH), we examined whether Slc14a1 gene has been changed in BCa with Slc14a1 break-apart DNA probes. We also performed immunohistochemistry evaluating bladder cancer markers.

Results: We found Slc14a1 gene rearrangement in one case of $\mathrm{BCa}$ from 14 patients. The patient is a 59year-old male with superficial BCa. Histology showed non-muscle invasive bladder transitional-cell carcinoma. Immunostaining was negative for Syn, CK7, CK20, Villin, and positive for HER2, BRCA1, GATA3.

Conclusions: We for the first time report a patient diagnosed with urothelial carcinoma accompanied with split Slc14a1 gene abnormality, a crucial gene in bladder.

\section{Background}

Bladder cancer (BCa) is the sixth most common cancer and occurs more often in men than in women. In 2004, the World Health Organization divided bladder tumors into muscle-invasive urothelial carcinoma and non-muscle invasive urothelial neoplasia (1). More than $70 \%$ of $\mathrm{BCa}$ patients are superficial disease at initial diagnosis, whereas $30 \%$ are in muscle-invasive stage(1). An important clinical feature of $\mathrm{BCa}$ is an unusually high propensity for recurring than in any other solid cancer. More than $70 \%$ of patients with $\mathrm{BCa}$ will have a recurrence during the first two years after diagnosis $(2,3)$. The recurrences are often accompanied by grade and/or stage progression with a very poor prognosis $(4,5)$.

In human and some other animals, the urinary bladder is a special organ that is in constant contact with a high concentration of urea, 20-100 times higher than in blood. Urea is the major end-product of nitrogen metabolism and is excreted by the kidneys. Urea is a small molecule ( $60 \mathrm{Da})$ and water solubility, however urea permeability across lipid bilayers is very low. Movement of urea across the cell membrane is mediated by urea transporter (UT) proteins(6-9). In mammals, there are two subfamilies of UT, UT-A and UT-B, encoded by the S/c14a2 and S/c14a1 genes, respectively. UT-A urea transporters are mainly expressed in renal medulla and contribute to the kidney's ability to concentrate urine. UT-B has broadly tissue expression including bladder. Bladder urothelium only expresses UT-B (10-12). This was confirmed by an RNA-sequencing analysis showing high expression of S/c14a1 (UT-B) and the absence of Slc14a2 (UT-A) in bladder tissues (13). 
Evidences have shown that an excess of intracellular urea accumulation damages cells and cell functions (DNA damage, abnormal cell phenotype transformation, genetic pathway activation, etc.) (11, 14-16). Since the bladder stores urine, its urothelium is inevitably and constantly exposed to a higher concentration of urea than any other tissues. Therefore, the urothelial UT-B stands in a key position to prevent urea-induced insults by lowering intracellular urea levels. To support it, bladder urothelium expresses the most abundant urea transporter UT-B in vivo (10). Disfunction of UT-B will cause intracellular urea accumulation and profoundly affect cells. The impaired urothelial cells are then vulnerable to be attacked by urea and/or by carcinogen in urine, a potential important mechanism of tumorigenesis in $\mathrm{BCa}$ (17).

We previously reported no or lower level of UT-B expression both at mRNA and protein levels in BCa. We also found that, in some BCa patients, the BCa expresses a mutant UT-B with a 24-nt in-frame deletion (del24) in exon 4. Or a low amount of UT-B is expressed but the UT-B protein glycosylation is unsialylated (17). All these changes of UT-B gene and/or protein contribute to the reduced urea transport activity in BCa.

When examining UT-B mRNA expression by RT-PCR, we noticed that UT-B mRNA was undetectable in some BCa patients (17). To figure out whether it could be due to UT-B genomic gene (S/C14a1) alteration, we collected 14 cases of $\mathrm{BCa}$ and performed fluorescence in situ hybridization (FISH). We found UT-B gene rearrangement occurred in one patient. This is the first report of genomic abnormalities of split SLC14A1 gene identified in BCa.

\section{Methods}

\section{Patients and tissue samples}

We collected 14 patients with BCa recently admitted in our hospital. The patient group was comprised of 11 men and 3 women, aged $41-79$ years.

Fresh tissues were obtained from surgical specimens and fixed in $10 \%$ formalin. Paraffin tissue blocks were made as standard technique, and 3 micrometer sections were prepared for pathological diagnosis, immunohistochemistry (IHC), and FISH test. Hematoxylin and eosin (HE) stained slides were reviewed independently by two senior pathologists. All 14 cases showed classic histopathological features of bladder urothelial cancer. 9 patients were low grade transitional cell carcinomas (LGTCC) and 5 patients were high grade transitional cell carcinomas (HGTCC).

This study was conducted under the approval by the Clinical Research Ethics Committee of Huai'an Hospital, Nanjing Medical University. A signed informed consent was obtained from all included patients for the use of tissue samples for this study.

\section{FISH analysis}


FISH was performed using S/c14a 1 break apart rearrangement dual color probe in this experiment. The probe consists of two combinations, a 200 kb of DNA (RP11-1114E12) at the centromeric side of Slc14a 1 gene being labelled by the tetramethyl rhodamine with a red fluorescence signal, a 190 kb of DNA (RP11-366J11) located in the telomeric side being marked by green fluorescence. RP11 bacterial artificial chromosome (BAC) clones with human genomic DNA were purchased from UCSF Benioff Children's Hospital Oakland. Plasmid DNAs were prepared by NucleoBond Xtra BAC large construct kit (Takara, 740436.25). DNA probes were fluorescent labelled using Nick translation DNA labeling system (Enzo-GEN111).

The slides were reviewed by a histologist to determine representative tumor areas for FISH test. Three micrometer thick sections were de-paraffinized in xylene, dehydrated with ethanol, pre-treated in $90^{\circ} \mathrm{C}$ water for 30 minutes, and then incubated with $1 \mathrm{mg} / \mathrm{ml}$ pepsin (Amresco) solution at $42^{\circ} \mathrm{C}$ for $15 \mathrm{~min}$.

The break-apart S/c14a1 probe set including human Cot-1 DNA was applied to individual slides. Human Cot-1 DNA (Fisher, 15279011) was used to block non-specific sequences. The slides were immediately covered with a coverslip and sealed with rubber cement. After denatured at $86^{\circ} \mathrm{C}$ for $8 \mathrm{~min}$, the sections were incubated for 16 hours at $38^{\circ} \mathrm{C}$ using Automated ThermoBrite FISH System (Leica Biosystems). Post-hybridization washes were carried out with $2 \times$ SSC for $3 \mathrm{~min}$ at room temperature followed by $2 \mathrm{X}$ SSC $/ 0.1 \% \mathrm{NP}-40$ solution at $72^{\circ} \mathrm{C}$ for $5 \mathrm{~min}$ and gradient dehydration in $70 \%, 85 \%$ and $100 \%$ ethanol. The sections were air-dried, protected from light and mounted with Fluorescence Mounting Medium containing DAPI (Sigma F6057). The fluorescence was viewed under Olympus FV1000 Upright fluorescence microscope. The fluorescence signals were evaluated in 50 nuclei for each tumor core under a 100x immersion objective.

\section{Results}

\section{Identification of split UT-B gene (S/c14a1) in BCa}

Gene split has been demonstrated in several cancers (18-20). In this study, we examined the rearrangement nature of SIc14a1 gene at 18q12.3 locus by FISH in tissue samples obtained from 14 cases of BCa. The S/c14a1 break apart DNA probes, which are labeled with different fluorescences, flanked at telomeric and centromeric sides of S/c14a 1 gene. When the S/c14a 1 gene break apart occurred, the signals are changed from merged yellow to single red and green as positive of UT-B gene split. At least 50 cells were analyzed for each sample. According to Noda's diagnostic criteria (21) for MAML2 gene split in mucoepidermoid carcinoma, we considered the positive Slc14a1 rearrangement if > 10 split signals of 50 nuclei were found.

In 13 cases of BCa patients, the hybridization signals of S/c14a1 break-apart probe showed two very close red and green colors with partially overlapped yellow colors indicating normal unbroken S/c14a1 gene. Fig. 1A showed a representative image of FISH results without UT-B gene split. However, in one patient (case 7), break-apart signal patterns of Slc14a1 gene were identified. As shown in Fig. 2A, 
separated red and green signals were observed. Total 50 cell nuclei were counted, and 36 nuclei showed break-apart signals, suggesting S/c14a1 gene rearrangements occurred in cancer cell chromosomes.

\section{Case presentation}

The patient (case 7) with the split UT-B gene was a 59-year-old male. He was admitted to a hospital with the complaint of gross hematuria for 6 days. There was no abdominal or flank pain and other abnormal finding. No lymphadenopathy was identified. No abnormal laboratory findings were noted. The patient did not have family history of $\mathrm{BCa}$. Ultrasonography revealed a size of $2.8 \times 1.7 \mathrm{~cm}$ mass lesion located on the rear wall and dome of the bladder. Bladder tumor was diagnosed. In cystoscopic examination, papillary tumoral lesions $3.0-\mathrm{cm}$ in total diameter were seen on the left wall of the bladder and $2 \mathrm{~cm}$ to the left ureteric orifice. Transurethral resection of bladder tumor (TURBT) was performed. The resected tissues were sent to the pathologic lab. Pathological examination showed high grade urothelial carcinoma. Immunohistochemistry analysis showed HER2 (3+), Syn (-), BRCA1(2+), GATA3 (3+), Ki-67 $(30 \%+)$, CK7 (-), CK20 (-), Villin (-), p53 ( \pm$)$.

\section{Discussion}

$\mathrm{BCa}$ is a complex and heterogeneous disease caused by both genetic and environmental factors. The "urogenous contact hypothesis" proposed by Braver (22) in 1987 is still prevalent in the etiology of BCa. However, one important factor that we may have ignored in bladder carcinogenesis is urea. The urea concentration in urine is $20-100$ times higher than that in blood in humans $(23,24)$. Interestingly, the risk of $\mathrm{BCa}$ for people with spinal cord injuries is $16-28$ times higher than that for the general population (25, 26), underscoring the important role of endogenous factors, including urea, in the bladder tumorigenesis.

Considering that the bladder urothelium is bathed in fluid with a high urea concentration and the toxicity of intracellular urea accumulation, the urea transporter is extremely important for bladder urothelium by lowering intracellular urea levels. Experimental studies have shown that deletion of UT-B gene causes urea accumulation in urothelium $\sim 9$ times higher in UT-B knockout mice $(11,27)$. This is accompanied by increased cell DNA damage, apoptosis and diminished arginine metabolism $(11,27)$. Therefore, loss of UT-B protection will render urothelial cells at risk under constantly high urea insult, then either directly activates genetic pathways that induce BCa or synergistically increases BCa risk by facilitating other carcinogen-induced mechanisms of BCa. In 2011, genome-wide association studies (GWAS) from two independent groups $(28,29)$ reported a number of gene variants of nucleotide polymorphisms within SLC14A1 (UT-B gene) on chromosome 18q12.3, are associated with risk of developing BCa in humans, suggesting the possible tumor suppressor role of UT-B in BCa.

Genomic alterations are quite common in $\mathrm{BCa}$ (1). Previous gene analysis revealed three types of UT-B gene abnormality in $\mathrm{BCa}$ (17): (1) no or under-detectable mRNA expression; (2) truncated short form of UT-B; (3) UT-B with a 24-nt in-frame deletion (del24) in exon 4 (UT-B $\triangle 24)$. In this study, we attempted to figure out whether in some BCa patients the absence of UT-B mRNA expression (17) measured by RT-PCR 
is due to $S / c 14 a 1$ gene rearrangement. Using a set of S/c14a1 break apart DNA probes, we performed FISH test by using FFPE tissue sections from 14 BCa patients. A patient of a 59-year-old male diagnosed with superficial, non-muscle invasive transitional-cell carcinoma clearly showed split Slc14a1 gene signals (Figure 2). This is the first report demonstrating a case of S/c14a1 gene rearrangement in BCa. Due to the smaller sample size, currently we are not able to characterize whether the Slc14a1 gene abnormality found in this study is associated with tumor cell invasion, metastatic spread, aggressiveness, tumor progression, recurrence and clinical outcomes. Another open question worth pursuing in the future is to find the fusion partners of the split S/c14a1 gene.

\section{Conclusions}

UT-B plays a crucial role in bladder, a unique organ dealing with high concentrated urea. Aberrant (due to gene mutation) or absent UT-B expression causes urea accumulation in urothelial cells. The high intracellular urea accumulation will result in bladder cell dysfunction and may either directly and/or indirectly promote $\mathrm{BCa}$ tumorigenesis. Although the S/c14a 1 as a new urinary BCa susceptibility gene was appreciated $(28,29)$, the role and the molecular mechanism of the UT-B in bladder oncogenesis have not been well explored to date. In this study, we for the first time report a case of S/c14a1 gene rearrangement in $\mathrm{BCa}$. Investigation are needed to further substantiate this finding and determine whether the S/c14a1 gene rearrangement is associated with stage, grade, recurrence, and overall survival.

\section{List Of Abbreviatons}

$\mathrm{BCa}$ Bladder cancer

UT Urea transporter

GWAS Genome-wide association studies

FISH Fluorescence in situ hybridization

IHC Immunohistochemistry

LGTCC Low grade transitional cell carcinoma

HGTCC High grade transitional cell carcinoma

\section{Declarations}

\section{Ethics approval and consent to participate}

The Clinical Research Ethics Committee of Huai'an Hospital, Nanjing Medical University approved this study (No. hasyy20130729003). An approved written informed consent was obtained from all participants. 


\section{Consent for publication}

Written consent was obtained from the patient to publish this case report.

\section{Availability of data and material}

The datasets used and/or analyzed during the current study available from the corresponding author on reasonable request.

\section{Competing interests}

The authors declare that they have no competing interests.

\section{Funding}

This work was supported by grants from Huai'an Promotion Project for science and technology international cooperation (HAC201708) to S.S. Natural Science Foundation of Huai'an (HAB201801) to X. L. and National Natural Science Foundation of China 81620108029 to B.Y.

The funds provided were used to finance laboratory expenses (materials and reagents). The funder had no role in the design of the study, the collection of data, the analysis and interpretation of results, or in writing the manuscript.

\section{Authors' contributions}

ZG, XN carried out the experiments and data collection; GF, BY, GC, SS analyzed and interpreted data; GC, SS concepted and designed the experiments; GC, SS wrote the manuscript. All authors have read and approved the manuscript.

\section{Acknowledgements}

Not Applicable

\section{References}

1. Ye F, Wang L, Castillo-Martin M, McBride R, Galsky MD, Zhu J, Boffetta P, Zhang DY, Cordon-Cardo C. Biomarkers for bladder cancer management: present and future. Am J Clin Exp Urol 2014; 2, 1-14.

2. Siegel RL, Miller KD, Jemal A. Cancer statistics, 2015. CA Cancer J Clin 2015; 65, 5-29.

3. Bellmunt J, Nadal R. Urothelial cancer in 2017: Changes in expectations for metastatic urothelial carcinoma. Nat Rev Clin Oncol 2018; 15, 73-74.

4. Al-Sukhun S, Hussain M. Current understanding of the biology of advanced bladder cancer. Cancer 2003; 97, 2064-2075.

5. Netto GJ, Tafe LJ. Emerging Bladder Cancer Biomarkers and Targets of Therapy. Urol Clin North Am $2016 ; 43,63-76$. 
6. Sands JM. Mammalian urea transporters. Annu Rev Physiol 2003; 65, 543-566.

7. Sands JM. Critical role of urea in the urine-concentrating mechanism. J Am Soc Nephrol 2007; 18, 670-671.

8. Li X, Chen G, Yang B. Urea transporter physiology studied in knockout mice. Front Physiol 2012; 3, 217.

9. Klein JD, Blount MA, Sands JM. Urea transport in the kidney. Compr Physiol 2011; 1, 699-729.

10. Yang B, Bankir L, Gillespie A, Epstein CJ, Verkman AS. Urea-selective concentrating defect in transgenic mice lacking urea transporter UT-B. J Biol Chem 2002; 277, 10633-10637.

11. Dong Z, Ran J, Zhou H, Chen J, Lei T, Wang W, Sun Y, Lin G, Bankir L, Yang B. Urea transporter UT-B deletion induces DNA damage and apoptosis in mouse bladder urothelium. PLoS One 2013; 8 , e76952.

12. Walpole C, Farrell A, McGrane A, Stewart GS. Expression and localization of a UT-B urea transporter in the human bladder. Am J Physiol Renal Physiol 2014; 307, F1088-1094.

13. Koutros S, Baris D, Fischer A, Tang W, Garcia-Closas M, Karagas MR, Schwenn M, Johnson A, Figueroa J, Waddell R, Prokunina-Olsson L, Rothman N, Silverman DT. Differential urinary specific gravity as a molecular phenotype of the bladder cancer genetic association in the urea transporter gene, SLC14A1. Int J Cancer 2013; 133, 3008-3013.

14. Zou Q, Habermann-Rottinghaus SM, Murphy KP. Urea effects on protein stability: hydrogen bonding and the hydrophobic effect. Proteins 1998; 31, 107-115.

15. Michea L, Ferguson DR, Peters EM, Andrews PM, Kirby MR, Burg MB. Cell cycle delay and apoptosis are induced by high salt and urea in renal medullary cells. Am J Physiol Renal Physiol 2000; 278, F209-218.

16. Zhang Z, Dmitrieva NI, Park JH, Levine RL, Burg MB. High urea and $\mathrm{NaCl}$ carbonylate proteins in renal cells in culture and in vivo, and high urea causes 8-oxoguanine lesions in their DNA. Proc Natl Acad Sci U S A 2004; 101, 9491-9496.

17. Hou R, Alemozaffar M, Yang B, Sands JM, Kong X, Chen G. Identification of a Novel UT-B Urea Transporter in Human Urothelial Cancer. Front Physiol 2017; 8, 245.

18. Soda M, Choi YL, Enomoto M, Takada S, Yamashita Y, Ishikawa S, Fujiwara S, Watanabe H, Kurashina K, Hatanaka H, Bando M, Ohno S, Ishikawa Y, Aburatani H, Niki T, Sohara Y, Sugiyama Y, Mano $\mathrm{H}$. Identification of the transforming EML4-ALK fusion gene in non-small-cell lung cancer. Nature 2007; 448, 561-566.

19. Savage KJ, Johnson NA, Ben-Neriah S, Connors JM, Sehn LH, Farinha P, Horsman DE, Gascoyne RD. MYC gene rearrangements are associated with a poor prognosis in diffuse large B-cell lymphoma patients treated with R-CHOP chemotherapy. Blood 2009; 114, 3533-3537.

20. Rogers TM, Arnau GM, Ryland GL, Huang S, Lira ME, Emmanuel Y, Perez OD, Irwin D, Fellowes AP, Wong SQ, Fox SB. Multiplexed transcriptome analysis to detect ALK, ROS1 and RET rearrangements in lung cancer. Sci Rep 2017; 7, 42259. 
21. Noda H, Okumura Y, Nakayama T, Miyabe S, Fujiyoshi Y, Hattori H, Shimozato K, Inagaki H. Clinicopathological significance of MAML2 gene split in mucoepidermoid carcinoma. Cancer Sci 2013; 104, 85-92.

22. Braver DJ, Modan M, Chetrit A, Lusky A, Braf Z. Drinking, micturition habits, and urine concentration as potential risk factors in urinary bladder cancer. J Natl Cancer Inst 1987; 78, 437-440.

23. Yang B, Bankir L. Urea and urine concentrating ability: new insights from studies in mice. Am J Physiol Renal Physiol 2005; 288, F881-896.

24. Spector DA, Yang Q, Wade JB. High urea and creatinine concentrations and urea transporter B in mammalian urinary tract tissues. Am J Physiol Renal Physiol 2007; 292, F467-474.

25. Hess MJ, Zhan EH, Foo DK, Yalla SV. Bladder cancer in patients with spinal cord injury. J Spinal Cord Med 2003; 26, 335-338.

26. Bothig R, Kurze I, Fiebag K, Kaufmann A, Schops W, Kadhum T, Zellner M, Golka K. Clinical characteristics of bladder cancer in patients with spinal cord injury: the experience from a single centre. Int Urol Nephrol 2017; 49, 983-994.

27. Li X, Ran J, Zhou H, Lei T, Zhou L, Han J, Yang B. Mice lacking urea transporter UT-B display depression-like behavior. J Mol Neurosci 2012; 46, 362-372.

28. Garcia-Closas M, Ye Y, Rothman N, Figueroa JD, Malats N, Dinney CP, Chatterjee N, Prokunina-Olsson L, Wang Z, Lin J, Real FX, Jacobs KB, Baris D, Thun M, De Vivo I, Albanes D, Purdue MP, Kogevinas M, Kamat AM, Lerner SP, Grossman HB, Gu J, Pu X, Hutchinson A, Fu YP, Burdett L, Yeager M, Tang W, Tardon A, Serra C, Carrato A, Garcia-Closas R, Lloreta J, Johnson A, Schwenn M, Karagas MR, Schned A, Andriole G, Jr., Grubb R, 3rd, Black A, Jacobs EJ, Diver WR, Gapstur SM, Weinstein SJ, Virtamo J, Hunter DJ, Caporaso N, Landi MT, Fraumeni JF, Jr., Silverman DT, Chanock SJ, Wu X. A genome-wide association study of bladder cancer identifies a new susceptibility locus within SLC14A1, a urea transporter gene on chromosome 18q12.3. Hum Mol Genet 2011; 20, 4282-4289.

29. Rafnar T, Vermeulen SH, Sulem P, Thorleifsson G, Aben KK, Witjes JA, Grotenhuis AJ, Verhaegh GW, Hulsbergen-van de Kaa CA, Besenbacher S, Gudbjartsson D, Stacey SN, Gudmundsson J, Johannsdottir H, Bjarnason H, Zanon C, Helgadottir H, Jonasson JG, Tryggvadottir L, Jonsson E, Geirsson G, Nikulasson S, Petursdottir V, Bishop DT, Chung-Sak S, Choudhury A, Elliott F, Barrett JH, Knowles MA, de Verdier PJ, Ryk C, Lindblom A, Rudnai P, Gurzau E, Koppova K, Vineis P, Polidoro S, Guarrera S, Sacerdote C, Panadero A, Sanz-Velez JI, Sanchez M, Valdivia G, Garcia-Prats MD, Hengstler JG, Selinski S, Gerullis H, Ovsiannikov D, Khezri A, Aminsharifi A, Malekzadeh M, van den Berg LH, Ophoff RA, Veldink JH, Zeegers MP, Kellen E, Fostinelli J, Andreoli D, Arici C, Porru S, Buntinx F, Ghaderi A, Golka K, Mayordomo JI, Matullo G, Kumar R, Steineck G, Kiltie AE, Kong A, Thorsteinsdottir U, Stefansson K, Kiemeney LA. European genome-wide association study identifies SLC14A1 as a new urinary bladder cancer susceptibility gene. Hum Mol Genet 2011; 20, 4268-4281.

\section{Figures}



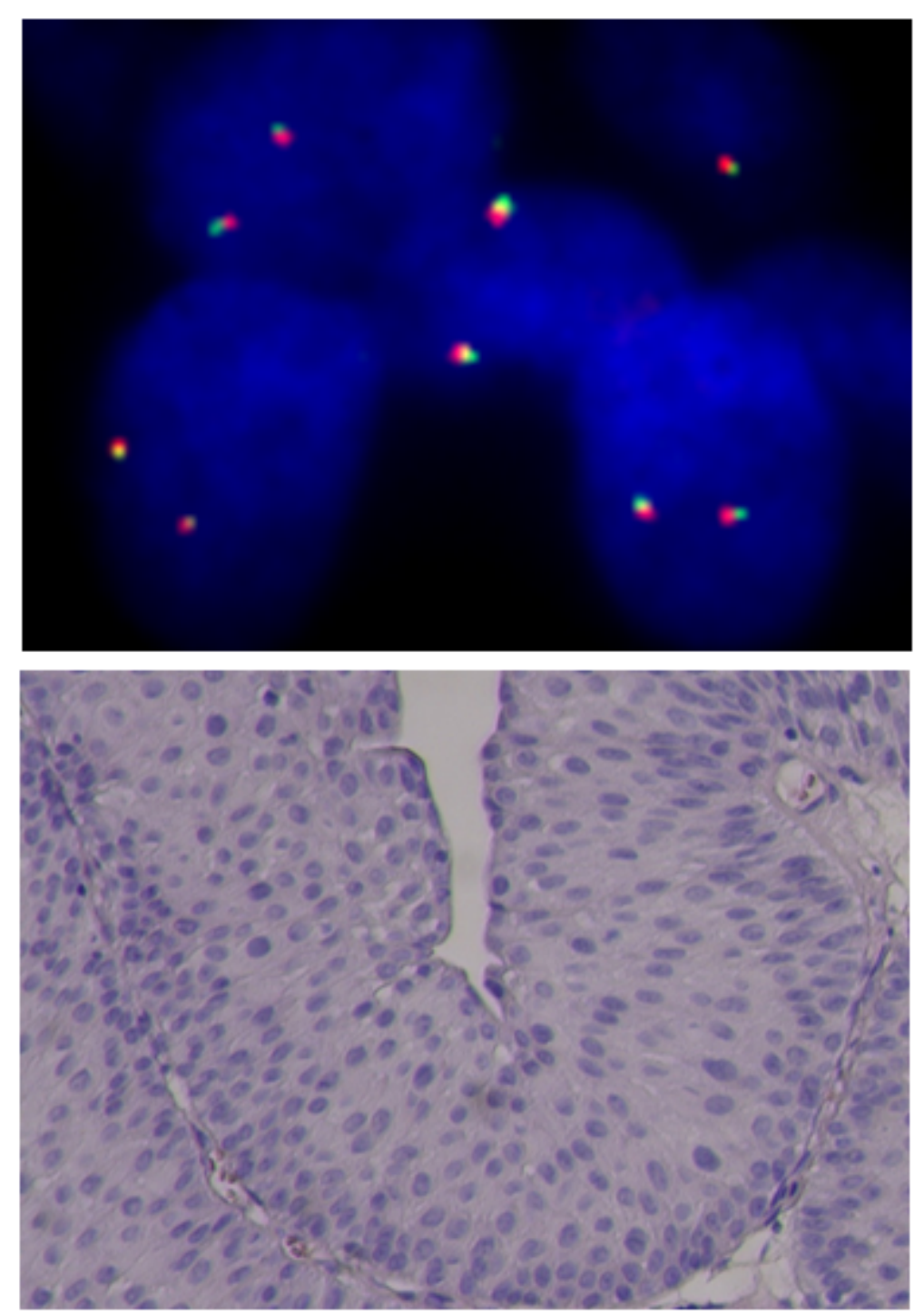

\section{Figure 1}

Case 3 of bladder cancer. A. FISH analysis using "break-apart" Slc14a1 probes showed a representative image of bladder cancer cell without UT-B gene split. Normal fusion signal indicated two close red and green colors with partial overlapped yellow color. B. Histology of case 3 shows typical morphology of bladder urothelial cancer. 

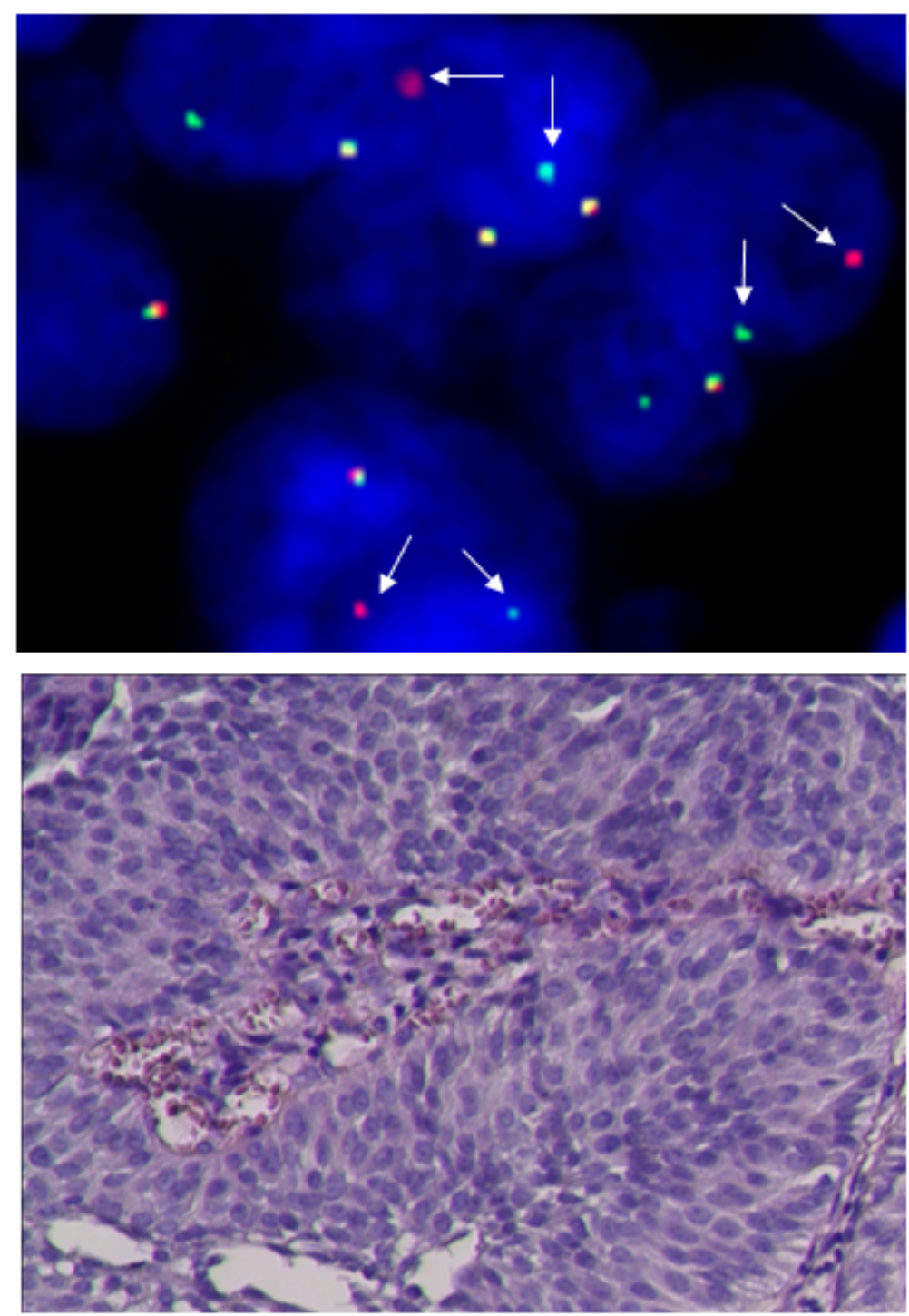

Figure 2

Case 7 of bladder cancer. A. FISH analysis of Case 7 shows some separated red dots and green dots (arrows) in cancer cells representing UT-B gene split. Normal fusion signals are two close red and green colors with partial overlapped yellow color. B. Histology of case 7 shows bladder urothelial cancer. 